Acta. Psycholugica 26 (1967) 148-160; (C) North-Holland Publishing Co., Amsterdam Not to be neproduced by photoprint or milrofilm without written pernission from the publisher

\title{
PERCEPTION WITHOUT AWARENESS
}

\author{
K. M. BÂNRE'TI-FUCHS 1 \\ University of Utrecht, Utrecht, The Netiherlands
}

\begin{abstract}
Two experiments were carried out in order to re-examine the phenomenon of subliminal perception: c.q. perception without awareness. Subliminal perception, c.q. perception withont awareness, was defined in terms of the subjects' ability to respond differentially to the cratent of: stimuli like words or digits, without having consciously identified their meaning.

In the first experiment, subliminal visual perception was examined in terms of the subjects' ability to respond differentially to Dutch stimulus words of positive versus negative emotional connotation, which were presented at such a low level of light interisity that the subjects were unable to perceive even their presence at the coinscious level. The critical nueasures of the ability to respond differentially were the associative reaction times.

In the second expe:iment, which was disguised as being related to extrasensory perception, the number ' 5 ' served as the visual stimulus and was pre. sented at such a marginal level of intensity that some of the subjects would cousciously perceive it, while the others did not. Howrver, all the subjects, also those of the latter category, were able to perceive and identify his stimulus when their attention. was explicitly called to it. The question was, whether those s:lbierts who did not perceive this marginal sujuraliminal stimulus at the constious level, would nevertheless be affected by it in the predicted direction, or not.

Perception without awareness could not bi demonstrated at either of these two intensities of stimulation. An attempt was made to explain the differences in results between these experirnents anil those which allegedly have demonstrated the phenomenon of visual perceprion without awareness.
\end{abstract}

The objective of this experimert was a re-examination of the vhenomenon of subliminal perception. It was mainly inspired by studies of Dixon (1958) and Furrer and ERIKSEN (1960). The principal question in their experiments was, uhether human subjects would be able to respond differentially to the visual prisentation of stimulus words, when these are presented subliminally, in other words, when the subjects are unable to identify consciususly the mearing of the stimulus

1 At present Chief Psychologist, The (Intario Hospital, St: Thomas, Ontario, C.unada. 
words. Each time one of these words was presented tachistoscopically at a subliminal level, the subjects had to respond with the very first word that came to their minu. Dixon registered the verbal responses, the association reaction times, and the galvanic skin responses. Fuhrer and Erikser did essentially the same, except that they did not use GSRs. One of the crucial measures of subliminal perception consisted of differential association reaction times to the emotionally positive versus the negative stimulus words. Significantly longer association reaction times to the group of emotionally negative subliminal stimulus words were considered to be an indication of subliminal percention. The implicit assumption was that, at the supraliminal level, the association reaction times to the emotionally negative stimulus words would be also significantly longer than the association reaction times to the positive stimulus words. This hypothesis had not been tested, however, and consequently the results of their experiments cannot be meaningfully interprete $\hat{i}$, as far as this measure of subliminal perception is concerned. Regarding the other crucial measures of subliminal perception, i.e., GSRs, and the matching of stimulus and response words after the subliminal stimulation, the results of the two above-mentioned experiments were contradictory. Dixon did find indications of subliminal perception, while Fuhrer and Eriksen dio nor.

The present study examined the phenomenon of subliminal perception, using differential association reaction times as the crucial measure of the subliminal effect. A pilot study with a group of thirty subjects had established the fact that, at the supraliminal level, the subjects indeed reacted differentially to the two groups of stimulus words used in this experiment. A significant number of subjects showed longer association reaction times to the group of emotionally positive stimulus words, than to the group of emotionaily negative stimulus words $(p=0.04$ Sign Test, two-tailed; $p=0.04$ Wilcoxon matched-pairs signed-ranks test, two-t:tiled). This result does not support the frequently made hyp sthesis that emotionally negative stimulus word; elicit longer association reaction times than emotionally positive stimulus words. This is $\mathbf{n}$ it entir $>y$ unexpected, however, since 'THumb and MARBE (1901) havi. show: already long ago, that there is a close relationship between assciation reaction time and frequency of association. Also the freq 10 : $y$ of the stimulus words in the spoken languag!: is probably a factor whic 1 may affect the association reaction times. In any case, sinc there are several uncontrolled variables influenc ng association 
reaction times apart from the emotional quality of the stimulus words, it is absolutely necessary to find out at the supraliminal level, whether or not the subjects respond differentially to the two groups of stimulus words. Since in the pilot study (BÁNRÉTI-FucHS, 1964) the subjects actually did give evidence of responding differentially to the two groups of stimulus words at the supraliminal level, the association reaction times may be used as a criterion for testing the phenomenon of subliminal perception, because we have no logical reason to expect that an existing close relationship between perception of the meaning of stimulus words ant association reaction tines would significantly change as a function of the degree of awareness of the meaning of the stimulus words., as long as the meaning of the stimule ws words is perceived by the subjects, consciously or unconsciously. In other words, if subliminal perception is a real phenomenon and not just an artifact, then the relaticaship betwe in perception of the meaning of the stimulus words and the asscciation reaction tinses should be the same, or at least very similar, at all level:; of awareness of the meaning of the stimulus words. If one does not postulate this hypothesis explicitly or implicitly, then this approach to examine the reality of the phenomenon of subliminal perception is inpos sible.

\section{EXPERIMENT 1}

\subsection{Wethod}

The stirnulus words were nouns of seven letters, chosen from the Dutch word count inventory of DE LA COURT (1937). It was attempted to select words structurally as similar as possible. The frequency of the words according to de la Cour: was 2/1000 000 in the Dutch written language. A total of 36 stimulus words were used for subliminal presenration, plus five words of the same length and frequency for assessing thresholds. From the 36 words a choic: of 14 crucial stimulus words was made, namely seven positive and sitven negative words, on whose emoticnal quality there was an interrater agreement of at least $87 \%$ as measured by Kotwer's (1958) Dutch version of the Osgood Semantic Differential (table 1). For the assessment of the emotional quality of the stimulus words the factor 'value' of the Semantic Differential was used. This rating was done by 31 persons, among whom the 20 subjects who had participated in the subliminal experiment all undergraduate psychology students). 
TABLE 1

List of the crucial stimulus words, and the degree of interrater agreement on their emotional qualiy.

\begin{tabular}{|c|c|c|c|}
\hline Stimulus word & Positive & Negative & Neutral \\
\hline toegift (bonus) & 28 & 1 & 2 \\
\hline novelle (novella) . . . . . . . & $2 \%$ & 0 & 4 \\
\hline ballade (ballad) $\ldots \ldots \ldots$ & 30 & 1 & 0 \\
\hline dialoog (dialogue) $\ldots \ldots \ldots$ & 29 & $\mathbf{0}$ & 2 \\
\hline vislist (violinist) $\ldots \ldots \ldots \ldots \ldots$ & 29 & 0 & 2. \\
\hline sterkte (strength) $\ldots \ldots \ldots$ & 28 & 0 & 3 \\
\hline festijn (feast) . . . . . . . & 30 & $\mathbf{0}$ & 1 \\
\hline blamage (blunder) . . . . . . & 1 & 29 & 1 \\
\hline gevloek (swearing) $\ldots \ldots \ldots$ & $\mathbf{0}$ & 31 & 0 \\
\hline vuilnis (dirt) . . . . . . . . . & 0 & 31 & j \\
\hline$\ldots \ldots$ & 1 & 28 & 2 \\
\hline klodder (smudge) . . . . . . . . . & $i$ & 29 & 1 \\
\hline$\cdots \cdots \cdot \cdots$ & 3 & 27 & 1 \\
\hline cholera (cholera) . . . . . . . . & 1 & 30 & 0 \\
\hline
\end{tabular}

The duration of the experiment was approximately two hours per subject. Threshold measurements were done with 5 different stimulus words successively, using the method of decreasing light intensity by manipulating the width of the opening of a sep trate shutter mounted on the projector. The threshold was defined as that light intensity - in terms of the width of the opening - at which the subject wis unable to perceive consciously even the presence of the stimulus word on the screen.

After the threshold measurements the subliminal stimuli wrere presented with a light intensity equivalent to the lowest threshold level minus $1 \mathrm{~mm}$ of the width of the opening. In total there were 108 presentations, or three series of 36 . The first series consisted of the presentation of blank slides, in the second series the stimulus words were projected in the originai order, and in th: third series in the reverse order. The presentation time was 5 se: per slide. The order of presentation of the slides was rotated and consequently each subject began with a different stimulus word. The association reaction times were automatically registered with the accuracy of $1 / 100$ sec. After each series of 36 presentations there was a rest period of one minute. 
The instruction was: 'I am going to project a number of words on this screen, one at a time, but with such a weak intensity that you will not be able to perceive even their presence on the screen at the conscious level. The signal that there is a word on the screen, is the light spot which you have seen just before (demonstrated). Wher this light spot appears on the sereen, simultaneously also a word is being projected in the same area, where you have seen the other words (during the threshold measurements). When the light spot disappears, simultaneousily also the siimulus word disappears from the screen. As soon as the light spot and the stimulus word appear on the screen, you should name the very first word that comes to your mind, regardless which word this mav be. You are, of course, not supposed to think of words in advance and name these at the cricial moment'.

After the subliminal presentation of the stimulus words, threshold measurements were taken for all stimulus words used during the subliminal presentation, in order to find out at which width of the opening of the shutter the stimulus words could be identified correctly. In this case, of course, the method of increasing the light intensity of the stimuli was used. These thieshold measurements were needed, since it had to be demonstrated that the light intensity of the stimulus words during the subliminai presentation had been really subliminal, in spite of possible adaptation processes during the course of presentation.

The last item on the program was the cvaluation of the emotional quality of the stimulus words by using the factor value of Kouwer's Semantic Differential (table 2). The stimulus words were presented to the subjec:s one at a time, and the order of presentation was rotaicd to avoid possible position effects.

TABLE 2

Items of Kouwer's Semantic Differential atsessing the factor 'value'

Goed

(Gocd)

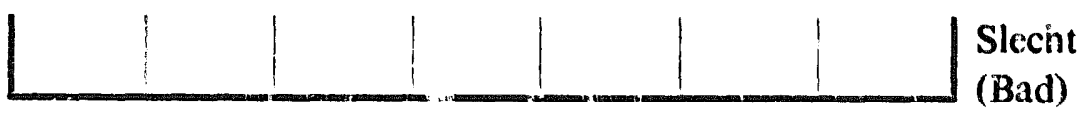

Mooi

(Nice)

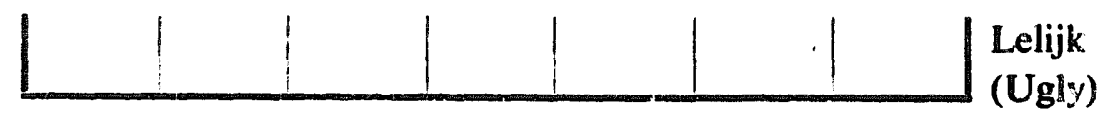

Waardevol

(Vahuable)

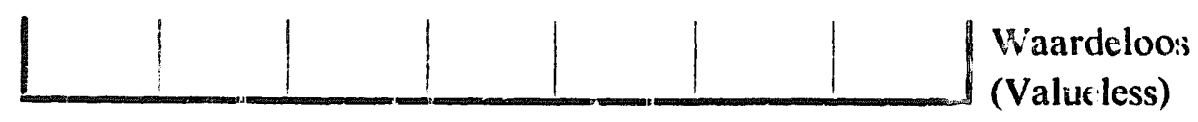




\subsection{Apparatus}

The subject was seated on an armchair, with his head comfortably on a headrest, situated between a screen in tront of him and two projectors behind him, mounted on a table in such a way that projection above the subject's head was always possible. The light it the room was on during the experiment, and the screen was continually illuminated by a reflector in order to eliminate shadows. Two synchronized projectors were used, one to present the stimulus words and the other to project the simultaneous light signal. The intensity of the stimuli was controlled by adjusting the openings of two synchronized shutters, one in front of each of ahe projectors, on which a millimeter scale was mounted, in order to be able to read directly the width of the opening of the shutter. At the time of the presentation of each sublininal stimulus word an electronic counter was activated by the projectors, which was stopped by a microphone voice key attached to the throat of the subject as soon as he responded by naming an association word. The association words were registered manually by the experimenter.

\subsection{Results and discussion}

A summary of the reaction times, the intensity of the stimulus words during subliminal presentation, and the lowest light intensity at which a stimulus wora could be correctly identified at the conscious level, are given in table 3 . The number of subjects with longer association reaction times to the group of positive stimulus words is greater than the number of subjects with longer association reaction times to the group of negative stimulus words, but the difference is statistically not significant ( $p=0.11$ Wilcoxon; $p=0.13$, Sign Test; one-tailcd). Although the results are in the expected direction, they still fail to demonstrate with a reasonable degree of reliability that the subjects were indeed responding differentially to the meaning and the exnotional quality of the subliminally presented stimulus words. Consequently, this experiment does not support the theory of subliminal perception. However, it does pose anothcr interesting question, namely whether subjects would respond differentially to those marginal supraliminal stimuli, of which they are unaware at the conscious level. If subjects do not respond differentially to these stimuli, then it would be also unrealistic to expect them to respond differentially to those stimuli, of which they, even in principle, cannot be aware at the conscious level. This question is examined in the following experiment. 
TABLE 3

Association reaction times

\begin{tabular}{clllll}
\hline Subject & $P$ & $P^{2}$ & $\mathrm{D} \%$ & $\mathrm{Pi}$ & Lit \\
\hline 1 & $37.98(\mathrm{sec})$ & $33.10(\mathrm{sec})$ & +6.86 & $4.50(\mathrm{~mm})$ & $8.50(\mathrm{~mm})$ \\
2 & 83.17 & 81.89 & +0.17 & 5.25 & 9.50 \\
3 & 39.71 & 44.40 & -5.57 & 5.50 & 9.50 \\
4 & 39.24 & 36.57 & +3.52 & 5.50 & 10.25 \\
5 & 50.06 & 50.05 & +0.01 & 5.50 & 9.50 \\
6 & 68.62 & 72.92 & -3.04 & 6.00 & 9.75 \\
7 & 50.21 & 45.90 & +4.48 & 5.50 & 10.75 \\
8 & 35.82 & 38.44 & -3.53 & 5.25 & 10.25 \\
9 & 21.73 & 19.39 & +5.69 & 4.75 & 10.25 \\
10 & 13.90 & 12.84 & +3.96 & 4.25 & 9.75 \\
11 & 32.38 & 33.01 & -0.96 & 4.50 & 10.00 \\
12 & 40.66 & 35.11 & +7.32 & 5.25 & 10.25 \\
13 & 21.15 & 19.71 & +3.52 & 5.50 & 9.25 \\
14 & 33.49 & 29.97 & +5.54 & 4.50 & 8.25 \\
15 & 17.25 & 15,64 & +4.89 & 5.25 & 7.75 \\
16 & 48.94 & 51.01 & -2.07 & 4.75 & 8.50 \\
17 & 13.71 & 15.84 & -7.21 & 4.25 & 8.75 \\
18 & 13.29 & 12.61 & +2.63 & 4.00 & 9.25 \\
19 & 34.17 & 38.22 & -5.59 & 4.00 & 10.00 \\
20 & 27.83 & 24.17 & +7.13 & 4.00 & 8.50 \\
\hline
\end{tabular}

Abbreviations

$P=$ sum total of the association reaction times to the crucial positive stimulus words of series 2 and 3 added.

$N=$ sum total of the association reaction tinies to the crucial negative stimulus words of series 2 and 3 added.

$D=$ differences between the positive and negative groups expressed in percentages.

$\mathrm{Pi}^{\mathrm{i}}=$ intensity of the stimuli during subliminal presentation, expressed in terms of the width of the shutter.

Lit $=$ lowest identification threshold, expressed in terms of the width of the shutter.

\section{EXPERIMERT 2}

This study was designed to examine the question, whether subjects would respond to a marginal supraliminal stir.ulus, which they are unaware of at the conscious level, but are able to perceive consciously when their attention is drawn explicitly to it. The important question was therefore, whether those subjects, who do not perceive the stimulus at the conscious level, would respond to it, or not. 


\subsection{Method and apparatus}

The equipment involved was the same as in the previous experiment. The subjects were 33 fresh first year psychology students. It was suggested that the experiment was meant to examine whether or not looking intensively at at brightly illuminated screen would influence their guessing behavior. The experiment implicitly made the impression that it was related somehow to extrasensory perception. The experimenter, who was sitting behind the subject, had a stack of 45 blank cards in his hands. The subjects were told that all of these circls contained a number in the range of 1 to 9 , and that the different numbers were not equally represented. Actually all cards were blank. The subject had to fix his glance on the brightly illuminated screen in front of him. He was told that the experimenter would each time look at the number on one of the cards and give the subject a signal, in the form of a small black circle projected on the screen, when he had to guess which number in the range of 1 to 9 the experimenter was looking at. The subject had to guess 45 times successively, at the end of which period he got a minute's rest. Then the whole procedure was repeated again. However, during one of the two series, alternately in either the first or the second series, the subject was presented not only with the black circle when he had to guess, but without his knowledge, slightly above the black circle also the number ' 5 ' was projected on the screen, simultaneously with the black sircle. The size of the number ' 5 ' on the screen was approximately $40 \mathrm{~mm}$, while the black circle had a diameter of $24 \mathrm{~mm}$. The intensity of the light with which the number ' 5 ' was presented during the experimental series, i.e. the series during which the number ' 5 ' was presented, was the same for all subjects. This optimal light intensity, which had been established in a pilot study prior to the experiment, was such that part of the subjects would perceive the stimulus at the conscious level, part of the subjects would not perceive it, while in principle all of the subjects would be able to perceive it at the conscious level when their attention would be explicitly drawn to it. After the guessing sessions followed a standardized interview consisting of eight questions (table 4), all directed at finding out whether the subject had perceived anything during the experimental series apart from the black circle. On the basis of his respcinses to these questions each subject was placed in one of three groups: (a) aware group, (b) partially-aware group, (c) unaware group. 
TAlile 4

List of questions asked during the interview

1. Wat vond u van deze proer? (How do you feel about this experiment?)

2. Hebt u misschien toch volgens een bepaald systeem gewerkt? (Have yon perhaps guessed according to some system after all?)

3. Weik cijfer hebt: $u$ het rneest frequent gegokt? (Which number have you called most frequently?)

4. Welk cijfer hebti $u$ het minst frequent gegokt? (Which number have you called least frequently?)

5. Is daar misschien een bepaalde recicin voor? (Is there perhaps some spec fic reason for it?)

6. Wat is het doel van deze proef? (What is the objective of this experiment?)

7. Wat is de functie van het scherm in deze proef? (What is the function of the screen in this expe-iment?)

8. Wat hebt $u$ eigenlijk ov het scherm precies gezien? (What exactly have you seen on the screen actually?)

In category (a) were classified those subjects, whose responses clearly revealed that they had perceived th. number ' 5 ' in the experimental series

In category (b) came those subjects who thought that in their 'imagination' they hai sometimes seen a certain number on the screen.

Category (c) consisted only of those subjects, who by their responses clearly suggested that they had seen nothing on the screen apart from the biack circle. To the question: 'What is the objective of this experiment?' these subjects responded wostly with some theory about extrasensory perception.

In order to make sure that all subjects met the requirement of being abe to perceive the stimulus when their attention was explicitly drawn to it, also threshold measurements were done after the interview. Only one singlo subject did not meet this criterion, and his data were consequently disizarded and not used for processing the results of the experiment.

In this experiment two hypotheses were tested:

(1) Subjects of the aware group are expected to call ('guess') the numbir ' 5 ' moi 2 frequently during the experimental series than during the control series since, due to their conscious awareness of the marginal suprali rinal stinau'us, they should respond to its suggestive influence. 
(2) Subjects of the unaware group are expected to call ('guess') the number ' 5 ' equally often both in the experimental and in the control series since, due to their lack of conscious awareness of the marginal supraliminal stimulus, they are not likely to respond to its suggestive influence.

\subsection{Results and discussion}

As can be seen from table 5 , both hypotheses were quite convincingly confirned. The presence of the marginal supraliminal stimulus strongly interfered with the guessing behavior of the aware subjects $(p<0.01$ Wilcoxon; $p<0.02$ Sign Test; two-tailed), while the subjects of the unaware group were evidently guessing at random ( $p=0.22$ Wilcoxon; $p=0.22$ Sign Test; two-tailed). In fact, the subjects of the unaware group called ' 5 ' more frequently in the control series than in the experimental series, although this difference was not significant. In any case, the unaware group did not show ary indication of responding to the marginal supraliminal stimulus. As mentioned before, the subjects of all three groups were able to perceive the marginal supraliminal stimulus, the number ' 5 ', when their attention was explicitly a $i$ awn to it. However, the three groups had nevertheless significantly different threshold levels. Under threshold is meant here the lowest light intensity of the stimulus, expressed in terms of the width of the opening of the shutter of the projector, at which the subject was still able to perceive and identify the stimulus at the conscious level, when his attention was explicitly directed to the stimulus. As table 6 shows, the aware group had the lowest thresholds, followed by the partially aware group, while the unaware group had the highest threshoids. According to the KruskalWallis one-way analysis of variance (SIEGEL, 1956), the differences in threshold leveis between the three groups were highly significant $(p<0.01)$. This is a nice and independent double-check on the reliability of the results of the interview for assessing the awareness of the subjects for the marginal supraliminal stimulus duri:g the experimental scries, since it is very likely that subjects with low threshold levels would be sooner consciously aware of a stimulus of marginal interisity than subjects with higher threshold levels.

Summarizing the results of this experiment we have to state that our subjects did not respond to the marginal supraliminal stimuius if they were: not consciously aware of it. This result, of course, casts grave 
TABLE 5

Frequency of guessing the number ' 5 '

\begin{tabular}{|c|c|c|c|c|c|c|c|c|c|}
\hline \multirow[b]{2}{*}{ Subject } & \multicolumn{3}{|c|}{$\begin{array}{l}\text { Aware } \\
\text { subjects }\end{array}$} & \multicolumn{3}{|c|}{$\begin{array}{l}\text { Partially aware } \\
\text { subjects }\end{array}$} & \multicolumn{3}{|c|}{$\begin{array}{l}\text { Unaware } \\
\text { subjects }\end{array}$} \\
\hline & $\mathbf{E}$ & C & D & $\mathbf{E}$ & C & D & $\mathbf{E}$ & C & $\mathbf{D}$ \\
\hline 1 & 9 & 7 & +2 & & & & & & \\
\hline 2 & 14 & 3 & $+\mathbb{1 1}$ & & & & & & \\
\hline 3 & & & & & & & 3 & 4 & -1 \\
\hline 4 & & & & & & & 6 & 6 & 0 \\
\hline 5 & & & & & & & 4 & 5 & -1 \\
\hline 6 & & & & ¿ & 1 & +3 & & & \\
\hline 7 & & & & 5 & 4 & +1 & & & \\
\hline 8 & & & & & & & 3 & 5 & --2 \\
\hline 9 & & & & & & & 3 & 6 & -1 \\
\hline 10 & 6 & 6 & 0 & & & & & & \\
\hline 11 & 6 & 4 & +2 & & & & & & \\
\hline 12 & 12 & 5 & +7 & & & & & & \\
\hline 13 & 5 & 4 & +1 & & & & $\cdots$ & & \\
\hline 1.4 & 5 & 3 & +2 & & & & & ${ }^{\circ}$ & \\
\hline $15 j$ & 13 & 4 & +9 & & & & & & \\
\hline 16 & & & & & & & 4 & 7 & -3 \\
\hline 17 & & & & & & & 11 & 5 & +6 \\
\hline 18 & & & & 5 & 0 & 15 & & & \\
\hline 15 & & & & 4 & 7 & -3 & & & \\
\hline 20 & & & & & & & 8 & 6 & +2 \\
\hline 21 & & & & & & & 5 & 5 & 0 \\
\hline 2.2 & 27 & 5 & +22 & & & & & & \\
\hline 23 & 8 & 6 & +2 & & & & & & \\
\hline 24 & & & & 4 & 5 & --1 & & & \\
\hline 25 & & & & & & & 6 & 5 & +1 \\
\hline 26 & & & & & & & 5 & 21 & -16 \\
\hline 27 & 8 & 6 & +2 & & & & & & \\
\hline 28 & & & & & & & 3 & 6 & -3 \\
\hline 29 & & & & & & & 5 & 6 & $\ldots-1$ \\
\hline 30 & & & & & & & 3 & 3 & 0 \\
\hline 31 & 2.3 & 6 & +17 & & & & & & \\
\hline 32 & & & & 12 & 5 & +7 & & & \\
\hline
\end{tabular}

di.bbreviations;

$E=$ frequency of gowesses of number ' 5 ' if the experimental series.

$\mathrm{C}=$ frequency of guessis of number ' 5 ' in the control series.

$D=$ difference in frectiencie; of gussing number ' 5 ' between the experimental and the control series. 
TAREE 6

Threshold !evels of the three groups, expressed in terms of the widith of the shutter (mrr)

\begin{tabular}{ccc}
$\begin{array}{c}\text { Aware } \\
\text { group }\end{array}$ & $\begin{array}{c}\text { Partially } \\
\text { aware group }\end{array}$ & $\begin{array}{c}\text { Unaware } \\
\text { group }\end{array}$ \\
\hline 9 & 9 & 9 \\
9 & 12 & 10 \\
9 & 12 & 11 \\
9 & 13 & 12 \\
10 & 14 & 13 \\
10 & 15 & 13 \\
11 & & 14 \\
11 & & 14 \\
$1 \%$ & & 15 \\
$1 \%$ & & 15 \\
12 & & 15 \\
13 & & 15 \\
& & 16 \\
\hline
\end{tabular}

douts at the effectiveness of those stimuli which are presentif $\mathbb{d}$ with an intensity, at which the stimulus cannot, even in principle, re nerceived and identified by the subjects at the conscious level. The $\mathrm{d}$ ference in results setween this experiment and those, which actualy did find a subliminal effect, may be at least partly due to the type $0: \mathbf{s}^{\prime}$ muii used.

In our experiments we used only stimuli which, apart from their puridy st ructural characteristics, also possessed a spəci ic, abstract meaning, such as the ineaning of a word, which refers tc so nething else than its own structural qualities. E.g., someone who has n.) knowledge of the English lang,uage, may perceive all structurai chas acteristics of: the word table: without being able to identify its abstrac $i \mathrm{~m}$ :aning. Using this type of stimuli it is considerably easier to find out in a reliable manner, whether the subject has really been aware of th: stimulus, or not. When stimuli are used which have only structurs!' qui lities, as often happens in experiments involving figural illusions, ile $\mathrm{c}$ ucial stimulus may be imbsded in a complex gestalt, but neverileles: influence the subject's perception, without his conscious awar:less of this crucial stinulus. However, is it in this case really ustified co co nolude that the subject was unaware of the stimulus at the cunscic us le rel, or would it be safer to state, that he was perhaps uaawar: of th: stimulus as a separate entity, due to the fact that it was imberld ed in another gestalt? 
According to us, in such a case it is nearly impossible to assess reliably the subject's awareness of the stimulus, and that is the reason why we prefer to use stimuli which have a very specific abstract meaning additional to their purely structural qualities. However, using stimuli which we consider adequate for the purposes of this type of experiments, ve did not find evidence that the subjects would be able to respond to stimuli of which they are not consciously aware.

\section{REFERENCES}

BánRéti-Fuchs, K. M., 1964. Problemen der subliminale perceptie. Experiment 5. Assen: Van Gorcum.

CourT, J. F. H. A. DE LA, 1937. De 'n est voorkomende woorden en woordcombineties in het Nederlanósch. Verslag van een onderzoek in opdracht van het Departement van Ordervijs en Eredienst.

Dixon, N. F., 1958. The effect of subliminal stimulation upon autonomic and verbal hehavior. J. Abn. Soc. Psychol. 57, 29-36.

Furrer, M. J. and C. W. ERIKSEN, 1960. The unconscious perception of the meaning of verbal stimuli. J. Abn. Soc. Psychol. 61, 432-439.

KouWER, B. J., 1958. Een bewerking van de polariteitsprofielenmethode van Osgood. Ned. Tijdschr. v. d. Psychol. 13, 1-14.

Siegel, S., 1956. Non-prametric statistics for the behavioral sciences. New York: McGraw-Hill.

Thumb, A. and K. MarBe, 1901. Experimentelle Untersuchungen üher die nsychologischen Grundlagen der sprachlichen Analogiebildung. l.eipzig. 